\title{
Gait of dairy cows on floors with different slipperiness
}

\author{
E. Telezhenko, M. Magnusson, and C. Bergsten ${ }^{1}$ \\ Department of Biosystems and Technology, Swedish University of Agricultural Sciences, PO Box 103, S-230 53 Alnarp, Sweden
}

\begin{abstract}
This study assessed the slip resistance of different types of solid flooring in cattle housing using a range of technical tests and gait analysis. Dynamic and static coefficient of friction, skid resistance, and abrasiveness were tested on concrete flooring with a smooth finish, a grooved pattern, or a tamped pattern, acidresistant mastic asphalt, soft rubber mats, and a worn slatted concrete floor. Coefficients of friction and skid resistance were tested under clean and slurry-soiled conditions. Linear kinematic variables were assessed in 40 cows with trackway measurements after the cows passed over the floors in a straight walk. All gait variables were assessed as deviations from those obtained on the slatted concrete floor, which was used as a baseline. The coefficient of friction tests divided the floors into 3 categories: concrete flooring, which had a low coefficient of friction (0.29-0.41); mastic asphalt flooring, which had medium values $(0.38-0.45)$; and rubber mats, which had high values $(0.49-0.57)$. The highest abrasion $(\mathrm{g} / 10 \mathrm{~m})$ was on the asphalt flooring (4.48), and the concrete flooring with a tamped pattern had significantly higher abrasiveness (2.77) than the other concrete floors (1.26-1.60). Lowest values on the skid-resistance tests (dry/wet) were for smooth concrete $(79 / 35)$ and mastic asphalt (65/47), especially with a slurry layer on the surface. Gait analysis mainly differentiated floors with higher friction and abrasion by longer strides and better tracking. Step asymmetry was lower on floors with high skid-resistance values. The most secure cow gait, in almost every aspect, was observed on soft rubber mats. Relationships between gait variables and physical floor characteristics ranged from average to weak (partial correlations 0.54-0.16). Thus, none of the physical characteristics alone was informative enough to characterize slip resistance. With reference to gait analysis, the abrasiveness of the hard surfaces was more informative than the coefficient of friction, but the effect of pattern was better detected by skid-resistance measurements. Consequently, several
\end{abstract}

Received October 26, 2016.

Accepted April 3, 2017.

${ }^{1}$ Corresponding author: christer.bergsten@slu.se physical characteristics are needed to objectively describe the slip resistance of cattle floors. Soft rubber mats gave better tracking than hard, solid floors, even with a grooved surface or a tamped pattern.

Key words: dairy cattle, concrete flooring, mastic asphalt, rubber mat, slipperiness, locomotion

\section{INTRODUCTION}

The flooring in walking and standing areas is one of the most important components of cattle housing because of its effects on animal health and welfare (Rushen and de Passille, 2009; Bergsten et al., 2015). Because it has direct contact with cows' feet, flooring affects locomotion, claw conformation, and claw health (Vokey et al., 2001; Telezhenko et al., 2009). Type of flooring is discussed mostly in relation to its slipperiness (Albutt et al., 1990): slippery floors impair locomotion and affect behavior and estrus detection (Rushen and de Passille, 2006; Palmer et al., 2012), and they also cause injuries associated with falling (Rushen and de Passille, 2009).

Central to the understanding of floor slipperiness is the coefficient of friction, a numerical ratio of the horizontal (frictional) force between the contact surfaces of 2 objects, and the vertical force (load) between those objects (Franck et al., 2007). Frictional force is the sum of several components (Grönqvist et al., 2001). Adhesion is a surface component of friction, due to the molecular bonds between the claw and the floor. Hysteresis is another component that occurs due to delayed recovery of the elastic parts of the claw's weight-bearing surface after dimple by a floor asperity. Abrasion or wear - a loss of substance at the claw-floor interface due to mechanical interlocking between a claw and a hard, rough floor surface - may also cause high frictional forces. Rough floors provide higher hysteresis and abrasion, and therefore better friction, especially if the floor is soiled and adhesion cannot play a significant role (Mckee and Dumelow, 1995). Skid resistance is another term for friction used in the automobile industry and transportation systems.

Concrete is the most common flooring surface used in conventional cattle housing. Although much research has described the adverse effects of concrete on cow 
locomotion and claw health, the majority of existing and newly built cattle facilities still use it as their firstchoice walkway flooring surface, because of its ease of installation and relatively low cost. New concrete surfaces usually have an appropriate level of friction (or are sometimes even too abrasive), but most lose their friction and abrasive properties over time because of mechanical and chemical degradation of the material (De Belie et al., 2000). Several solutions are available to reduce the slipperiness of concrete surfaces. The most common is to cut grooves in the surface (Mckee and Dumelow, 1995), and several practical solutions are available for grooving concrete. However, few controlled studies have compared concrete treatments aimed at increasing slip resistance and improving cow gait (Albutt et al., 1990). Other solutions to improve walking areas involve applying alternative surface materials, which can be hard and rough, such as epoxy resin with bauxite aggregates (Phillips and Morris, 2001) or mastic asphalt (Telezhenko et al., 2009), or soft, such as rubber mats (Rushen and de Passille, 2006; Flower et al., 2007).

Objective assessment of cow gait on different surfaces is a comprehensive way to evaluate the function of a floor. However, it is time-consuming to gather gait data, it requires special arrangements, and the results depend on environmental factors and individual variability (Flower et al., 2006, Telezhenko, 2009). It would be beneficial if gait tests could be replaced by more standardized technical floor tests. However, simply testing the coefficient of friction of a surface does not give a clear indication of its actual slip resistance (Grönqvist et al., 2001). Different tests that measure various characteristics of walkway surfaces are needed to provide more objective information about slip resistance. Phillips and Morris (2001) determined the coefficient of friction and abrasiveness of a floor in parallel with gait analysis. They measured coefficient of friction using a drag test of real cow claws, making the results more relevant to cattle locomotion. On the other hand, it is difficult to completely replicate test results due to variability in claw horn quality and claw shape between animals (Telezhenko et al., 2009). Despite demand from the dairy industry, there is a lack of research comparing common ways to decrease floor slipperiness in cattle facilities, along with their actual effects. Our prediction was that by a wider range of technical tests it would be possible to describe the slipperiness of floors as comprehensively as with gait analysis. The aim of the present study was to assess the function of common solid solutions for improving the traction of cattle flooring. To obtain a comprehensive evaluation of slip resistance, we characterized the floor surfaces using several technical tests, along with cow gait analysis.

\section{MATERIALS AND METHODS}

The study took place on the research farm of the Swedish University of Agricultural Sciences in Alnarp during the housing season, from October 2002 to February 2003. The flooring experiments were made in a slatted concrete walkway (30 m long and $2.20 \mathrm{~m}$ wide) stretching from the pens to the milking area. All cows were housed 8 mo from September to April in a freestall system with 4 equal-sized pens. Each pen had 21 freestalls, with 2 rows parallel to the manger and 1 computer-controlled concentrate feeding station along the outer wall. The freestalls measured $1.2 \times 2.4 \mathrm{~m}$ and were equipped with cubicle partitions (Solid; DeLaval, Tumba, Sweden) and 30-mm polymeric mats (Cow Mat CM30L; DeLaval). They were littered with sawdust, which was provided twice per week. The walkways $(2.20$ $\mathrm{m}$ wide, $13 \mathrm{~m}$ long) between the stall rows were of slatted concrete (single 125-mm concrete beams divided by $40-\mathrm{mm}$ slots). The cows were milked twice daily in a $2 \times 9$ herringbone parlor; the holding area had a solid concrete floor and a mechanical crowd gate, and it had room for a maximum of 50 cows. The cows were fed a mix ratio ad libitum twice daily at the manger (about $35 \mathrm{~kg}$ of grass-clover silage and $2 \mathrm{~kg}$ of grain per head per day at 50\% DM) plus concentrates (grain, soy, and supplements) according to milk production in the feeding station of each pen. All cows were grazed daily for $4 \mathrm{mo}$ from the beginning of May to the beginning of September before the study started. Claw trimming was performed twice (before and after the grazing period). Cows in the herd had generally a very good claw health; only 1 case of sole ulcer was recorded during the study period.

\section{Floor Types}

Each of the solid flooring types tested consisted of 5 concrete slabs measuring $2.0 \mathrm{~m} \times 2.2 \mathrm{~m}$, made onsite from the same batch of concrete of the same quality. The slabs were fitted together and made up a $2.2-\mathrm{m}$ $\times 10-\mathrm{m}$ portion of the original $30-\mathrm{m}$ walkway from the pens to the milking area. The rest of the slatted concrete walkway to the milking parlor was used for baseline measurements.

The following 6 flooring types were assessed:

1. Smooth concrete: The concrete was cast in a plywood mold, and the smooth concrete surface formed facing the plywood was tested.

2. Grooved concrete: Grooves $(8 \mathrm{~mm}$ wide and 5 mm deep) were cut in a diamond pattern (rhomboids with $80-\mathrm{mm}$ sides at a $60^{\circ}$ angle, $69 \mathrm{~mm}$ 
between grooves) in smooth concrete slabs (the previously tested smooth concrete).

3. Tamped concrete: A hexagonal pattern (55-mm edges) was tamped in the wet green concrete with a specially constructed manually driven roller, with grooves $8 \mathrm{~mm}$ wide and $7 \mathrm{~mm}$ deep.

4. Mastic asphalt: Acid-resistant, mastic asphalt (bitumen plus crushed stone-based filler; $25 \mathrm{~mm}$ thick; BINAB, Helsingborg, Sweden) was applied on top of the concrete slab. The surface of the asphalt was finished with natural rounded siliceous sand (maximum particle size of $0.5 \mathrm{~mm}$ ).

5. Rubber mats: Solid rubber mats with a pebbled surface $\left(1 \mathrm{~m}^{2}\right.$ each; KSL, Gummiwerk Kraiburg Elastik GmbH, Tittmoning, Germany) were attached together and installed on top of the concrete slabs. Total rubber thickness was $30 \mathrm{~mm}$, of which the underside had $15-\mathrm{mm}$ rubber studs. The hardness was determined to be $64^{\circ}$ Shore A.

6. Concrete slats: The control floor was made from pre-strengthened single concrete slats $(125 \mathrm{~mm}$ wide) installed with a 40-mm slot opening (ABetong, Sweden). This floor was used as the walkway to the milking parlor and had aged over 15 yr of use.

\section{Floor Measurements}

The different floor types were assessed under controlled laboratory conditions for several physical characteristics related to floor slipperiness. Friction and skid resistance were measured on clean and on soiled surfaces. For soiling, a thin layer of liquid manure (DM mean $13.6 \%$, range 12.7-14.6) was applied with a scrub brush. The abrasiveness of the floors could be assessed only on a clean, dry surface.

\section{Friction}

The floor coefficient of friction was assessed using test apparatus designed at the Department of Biosystems and Technology (Swedish University of Agricultural Sciences). The device worked according to the "drag method" (Nilsson, 1988). It included a test body made of polyethylene (hardness: $95^{\circ}$ Shore A) and shaped to resemble 2 claws of a dairy cow foot $(110 \mathrm{~mm}$ long and $106 \mathrm{~mm}$ wide in total). The test body was loaded with $211.5 \mathrm{~kg}(2,074.12 \mathrm{~N})$ and pulled horizontally at a constant speed $(0.02 \mathrm{~m} / \mathrm{s})$ along the floor by a hydraulic piston. The force required to pull the body along the floor was recorded by a load cell placed between the test body and the piston. The coefficient of friction was calculated as the ratio between the pulling force and the total vertical (normal) force on the test body. It was determined when the body was at rest [i.e., the static coefficient of friction (SCOF)], and when in motion [i.e., the dynamic coefficient of friction (DCOF)].

The DCOF was measured on each floor type 10 times on a clean surface and 12 times on a soiled surface. The SCOF was measured on each floor type 7 times on a clean surface and 8 times on a soiled surface. Different numbers of measurements were used because there was more variation in the DCOF values and in measurements on the soiled surfaces.

\section{Skid Resistance}

Another way to assess frictional forces is to measure skid resistance. We conducted the skid-resistance tests (SRT) according to ASTM E 303-93 (ASTM International, 1993), using a device that is well known in road construction. It consists of a dynamic pendulum-impact tester used to measure the energy loss when a rubber slider edge, positioned at the end of a pendulum, is propelled over the test surface. The more the swing is slowed, the higher the skid-resistance value. The SRT device can be used on dry, wet, or soiled surfaces (Chang et al., 2001). We made 5 swings of the pendulum at 3 different locations for each test floor type and surface hygiene (clean/soiled). The final SRT value was expressed as the mean of the 15 values obtained.

\section{Abrasiveness}

The abrasiveness of the dry, clean floors alone was assessed using a method described by Nilsson (1988) and later modified (Jönsson, 1998; Nilsson and Jönsson, 1998). A block of plaster (water:gypsum ratio of 0.65 ) was dragged for $10 \mathrm{~m}$ over the flooring surface. By weighing the block before and after the drag test, we determined the degree of abrasion; the greater the weight loss, the more abrasive the flooring. The plaster blocks had a floor contact area of $106.2 \mathrm{~cm}^{2}$, and their weight (including loading weight) before the drag test was $2.24 \mathrm{~kg}$. The abrasiveness was expressed as the mean weight loss of 3 measurements, each using a new plaster block.

\section{Gait Analysis}

Forty Swedish Holstein cows, lactating through the study period (29 in their first lactation, 6 in their second lactation and 5 in their third or more), were selected. The cows were part of another study in which they were scored weekly for lameness (Sprecher et al., 1997), and cows with clinical lameness (score $>2$ ) were 
not used in the present study. To assess gait on a particular test floor, we used a slatted concrete walkway (30 $\mathrm{m}$ long and $2.20 \mathrm{~m}$ wide) from the cubicles to the milking parlor. The different floor types were inserted in a $10-\mathrm{m}$ stretch of the walkway 3 wk before the locomotion studies commenced, so that all cows could become accustomed to all surfaces while walking over the walkway 4 times per day (back and forth to milking twice daily). All cows were tested on all floors in the following order: (1) smooth concrete slats, (2) tamped concrete, (3) grooved concrete, (4) rubber mats, and (5) mastic asphalt. The entire observation period was 5 mo.

We assessed the kinematic characteristics of cow gait on the different test floors using trackway measurements (Telezhenko, 2009) after the morning milking. Cows were walked one by one along the $30 \mathrm{~m}$ walkway at their own speed, but to make them walk continuously, a person followed them slowly at a distance of several meters. A thin layer of slurry with a small amount of lime powder was spread by scrub brush on the test flooring before each test run as way to make footprints visible. Each test run for each cow on the test flooring was preceded by trackway measurements on the concrete slat floor of the same walkway. Thus, every test floor was compared against the same control floor with its own baseline data at the same place, direction, and time.

The measurements of the trackways on the test floors consisted of 4 consecutive strides ( 2 from the left and 2 from the right side) after approximately $3 \mathrm{~m}$ from the beginning and $3 \mathrm{~m}$ from the end of the test floor stretch, to minimize effects of starting and finishing the stretch.

The following gait characteristics were recorded by the first author as described in Telezhenko (2009):

1. Stride length: the distance between 2 consecutive imprints of the same rear foot.

2. Step angle (pace angulation): the angle between the lines connecting the middle points of the line across the posterior aspects of the lateral and medial claws of 3 consecutive imprints of the rear feet.

3. Step asymmetry: the absolute value of the difference between the lengths of 2 consecutive steps (distance between 2 consecutive imprints of the left and right rear foot).

4. Tracking (overlap): the lengthwise distance between the posterior edges of the bulb of the front foot imprint and the next imprint of the rear foot on the same side. This trait had a positive value if the rear foot was placed ahead of the front foot and a negative value if it was placed behind.

5. Mediolateral displacement of rear feet: the sideways distance between the lateral edges of the front foot imprint and the next placement of the rear foot on the same side. This trait value was positive if the rear foot was placed laterally to the front foot and negative if it was placed medially.

To estimate the walking speed of the cow, we measured the time taken to walk the test course using a stopwatch.

\section{Statistical Analysis}

The outcomes from the technical floor tests were analyzed by one-way ANOVA, and multiple comparisons between the floors within surface condition (clean or soiled) were made using a Tukey adjustment (Minitab 15 software; Minitab Inc., State College, PA).

To correct for individual locomotor changes, all gait variables on test floors were analyzed as change from the baseline measurements on the reference floor (smooth concrete slats). The differences from baseline were calculated by subtracting the mean values of 4 measurements for each gait variable on concrete slats from the respective mean values of the gait variables on the solid floor, which was tested in the same run. The analysis of changes from respective baseline was chosen instead of using baseline measurements as a covariate, because less bias is shown in nonrandomized studies (van Breukelen, 2006).

The gait differences from respective baseline values were analyzed with a repeated-measures ANOVA using the REML method (JMP version 6.0; SAS Institute, Inc., Cary, NC) with parity as the between-subject fixed factor $(\mathrm{df}=2)$ and floor as the within-subject fixed factor $(\mathrm{df}=4)$ and cow as a random variable nested within parity. The Tukey HSD test was applied for multiple comparisons of least squares means.

To estimate the linear association between gait characteristics and physical floor characteristics within individuals, we used multiple regression analysis (JMP, version 5). The effects of cow and individual means for gait characteristics, from respective baseline value as a covariate, were forced in each model. Partial correlation coefficients between gait and physical floor characteristics were calculated according to the method described by Bland and Altman (1995). Abrasiveness data on rubber mats was excluded when calculating the relationship between abrasiveness and gait characteristics, because the abrasiveness test does not correctly 
describe the interaction between a soft surface and a claw.

\section{RESULTS}

\section{Coefficients of Friction}

The static and dynamic coefficients of friction for clean or soiled floor surfaces are presented in Table 1. Rubber mats showed the highest static and dynamic coefficients of friction, regardless of surface hygiene. Coefficients of friction measured on mastic asphalt were lower than those on rubber mats, but higher than those on concrete floors. Among the coefficients of friction measured on tamped concrete, only SCOF values on a clean surface exceeded those measured on other concrete floors. Otherwise, coefficients of friction for tamped concrete, static and dynamic and with different surface hygienes, were indistinguishable from those for other concrete floors. The presence of grooves on the smooth concrete flooring had no significant effect on coefficient of friction.

\section{Skid-Resistance Test}

Analysis of variance revealed significant differences across all flooring types (Table 1). On dry/clean surfaces, the highest SRT values were measured on rubber mats, followed by tamped concrete, grooved concrete, smooth concrete, and mastic asphalt. When a thin slurry layer was present, the SRT values decreased considerably, and the highest values were measured on tamped concrete, followed by rubber mats, grooved concrete, smooth concrete, and mastic asphalt. Concrete slats had the lowest SRT value in every comparison.

\section{Abrasiveness}

It was possible to measure floor abrasiveness only under dry conditions (Table 1). The highest abrasiveness was achieved on mastic asphalt, and the abrasiveness on tamped concrete was significantly higher than on the other concrete floors. Rubber mats had a very smooth surface and showed extremely low abrasiveness.

\section{Gait Analysis}

The characteristics of cow gait on the baseline floor (concrete slats)-particularly step angle and step asymmetry, which are closely related to lameness score (Telezhenko and Bergsten, 2005) - did not reveal any systematic change during the observation period (Table 2 ). Gait characteristics for the 5 different solid floors are presented as deviations from their respective baseline (measurements obtained on concrete slats at the same time) in Figures 1-6.

Cows walked somewhat faster on rubber mats, but we found no significant differences in walking speed across the floor types tested (Figure 1). Cows walked with considerably longer strides on rubber mats (Figure 2). Stride length on mastic asphalt and tamped concrete was shorter than on rubber mats, but longer than on grooved concrete, and smooth concrete had intermediate values. We observed similar differences for tracking distance (Figure 3), with the highest value for rubber mats, then tamped concrete and mastic asphalt, followed by grooved concrete and smooth concrete (although the differences between smooth concrete and tamped concrete and mastic asphalt, respectively, were not statistically significant).

Table 1. Static coefficient of friction (SCOF), dynamic coefficient of friction (DCOF), skid-resistance test $(\mathrm{SRT})$ value, and abrasion for the 6 floor types tested (mean $\pm \mathrm{SD}$ )

\begin{tabular}{lcccc}
\hline Flooring & SCOF & DCOF & SRT value & $\begin{array}{c}\text { Abrasion, } \\
\mathrm{g} / 10 \mathrm{~m}\end{array}$ \\
\hline Dry surface & & & & \\
Concrete slats & $0.37^{\mathrm{d}} \pm 0.010$ & $0.29^{\mathrm{d}} \pm 0.010$ & $48^{\mathrm{f}} \pm 0.6$ & $1.68^{\mathrm{c}} \pm 0.12$ \\
Solid smooth concrete & $0.38^{\mathrm{d}} \pm 0.014$ & $0.32^{\mathrm{c}} \pm 0.014$ & $79^{\mathrm{d}} \pm 0.5$ & $1.26^{\mathrm{c}} \pm 0.17$ \\
Grooved concrete & $0.36^{\mathrm{d}} \pm 0.018$ & $0.31^{\mathrm{c}} \pm 0.021$ & $84^{\mathrm{c}} \pm 0.0$ & $1.60^{\mathrm{c}} \pm 0.16$ \\
Tamped concrete & $0.41^{\mathrm{c}} \pm 0.025$ & $0.32^{\mathrm{c}} \pm 0.009$ & $94^{\mathrm{b}} \pm 0.7$ & $2.77^{\mathrm{b}} \pm 0.25$ \\
Mastic asphalt & $0.44^{\mathrm{b}} \pm 0.009$ & $0.38^{\mathrm{b}} \pm 0.005$ & $65^{\mathrm{e}} \pm 0.4$ & $4.48^{\mathrm{a}} \pm 0.22$ \\
Rubber mat & $0.49^{\mathrm{a}} \pm 0.017$ & $0.49^{\mathrm{a}} \pm 0.015$ & $119^{\mathrm{a}} \pm 1.0$ & $0.05^{\mathrm{d}} \pm 0.04$ \\
Slurry-covered surface & & & & - \\
Concrete slats & $0.38^{\mathrm{cd}} \pm 0.012$ & $0.28^{\mathrm{d}} \pm 0.008$ & $35^{\mathrm{f}} \pm 0.9$ & - \\
Solid smooth concrete & $0.39^{\mathrm{cd}} \pm 0.007$ & $0.29^{\mathrm{d}} \pm 0.007$ & $50^{\mathrm{d}} \pm 1.1$ & - \\
Grooved concrete & $0.38^{\mathrm{d}} \pm 0.009$ & $0.30^{\mathrm{c}} \pm 0.012$ & $52^{\mathrm{c}} \pm 0.4$ & - \\
Tamped concrete & $0.39^{\mathrm{c}} \pm 0.011$ & $0.30^{\mathrm{c}} \pm 0.010$ & $64^{\mathrm{a}} \pm 0.9$ & - \\
Mastic asphalt & $0.45^{\mathrm{b}} \pm 0.009$ & $0.38^{\mathrm{b}} \pm 0.006$ & $47^{\mathrm{e}} \pm 0.7$ & - \\
Rubber mat & $0.57^{\mathrm{a}} \pm 0.014$ & $0.50^{\mathrm{a}} \pm 0.014$ & $61^{\mathrm{b}} \pm 0.9$ & - \\
\hline
\end{tabular}

${ }^{\mathrm{a}-\mathrm{f}}$ Values with different superscript letters within each column and treatment (clean or soiled) indicate significant difference $(P<0.05)$. 
Table 2. Gait characteristics of 40 cows on a concrete slatted floor, tested at 3-wk intervals [used as baseline (BL) for smooth concrete (BL-1), tamped concrete (BL-2), grooved concrete (BL-3), rubber mats (BL-4), mastic asphalt (BL-5); LSM \pm SEM]

\begin{tabular}{|c|c|c|c|c|c|c|c|c|c|c|}
\hline \multirow[b]{2}{*}{ Item } & \multicolumn{2}{|c|}{ Baseline 1} & \multicolumn{2}{|c|}{ Baseline 2} & \multicolumn{2}{|c|}{ Baseline 3} & \multicolumn{2}{|c|}{ Baseline 4} & \multicolumn{2}{|c|}{ Baseline 5} \\
\hline & LSM & SEM & LSM & SEM & LSM & SEM & LSM & SEM & LSM & SEM \\
\hline Stride length, cm & 149.54 & 1.59 & 150.02 & 1.52 & 148.67 & 1.53 & 149.80 & 1.36 & 150.94 & 1.61 \\
\hline Step angle, ${ }^{\circ}$ & 147.94 & 1.58 & 146.77 & 1.49 & 146.76 & 1.51 & 147.44 & 1.28 & 148.28 & 1.61 \\
\hline Tracking, cm & -6.02 & 1.57 & -5.64 & 1.54 & -5.78 & 1.54 & -5.41 & 1.45 & -4.19 & 1.59 \\
\hline Step asymmetry, $\mathrm{cm}$ & 3.42 & 0.53 & 4.42 & 0.48 & 4.13 & 0.49 & 4.07 & 0.36 & 4.31 & 0.54 \\
\hline
\end{tabular}

For step asymmetry (Figure 4), smooth concrete and mastic asphalt showed the highest magnitude of asymmetry, and tamped concrete and rubber mats showed the lowest. Step angle was highest on mastic asphalt and lowest on grooved concrete (Figure 5).

Mediolateral displacement of the rear feet was below the baseline for all solid floors, with the highest value obtained on smooth concrete and the lowest (least displacement) on mastic asphalt (Figure 6).

\section{Relationship Between Physical Floor Characteristics and Cow Gait}

The partial correlations between the physical properties of the flooring types tested and cow gait characteristics are presented in Table 3.

Stride length and tracking showed significant positive relationships with all physical floor characteristics tested. Both for DCOF and SCOF, correlations were somewhat higher for physical characteristics assessed on the dry floors. The association between stride length and coefficients of friction was stronger than for skid resistance. On the other hand, step asymmetry was mainly correlated with SRT values. Step angle showed

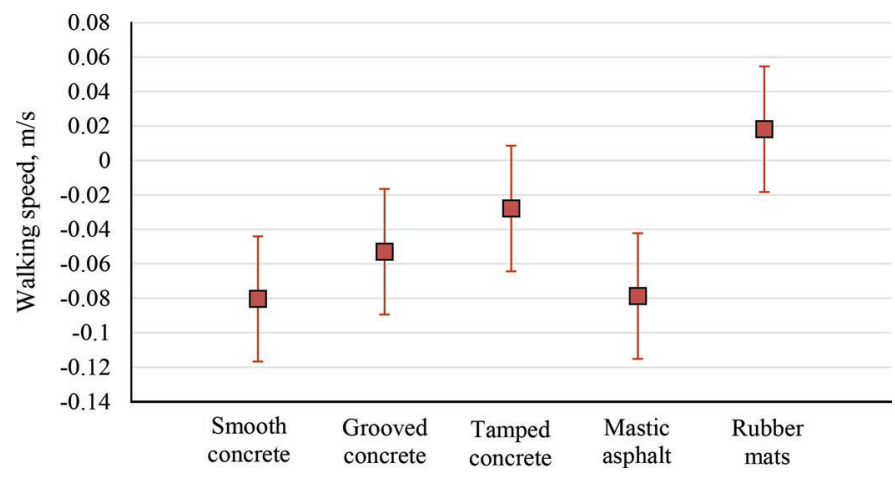

Figure 1. Walking speed $(\mathrm{m} / \mathrm{s})$ of cows on 5 different floors, presented as the difference from the baseline concrete slatted floor (LSM \pm SEM). Values did not differ significantly $(P>0.05)$. Color version available online. a significant positive correlation only with abrasion, and we found no significant relationships between mediolateral displacement and physical floor traits.

\section{DISCUSSION}

The drag test divided the floors into 3 categories: concrete flooring, with low coefficients of friction, irrespective of whether the floors were smooth, tamped, grooved, or slatted; mastic asphalt flooring, with medium values; and rubber mats, with high coefficients of friction. Higher abrasiveness differentiated tamped concrete from the other concrete floors, but the highest abrasion was obtained with mastic asphalt. Skid-resistance tests showed the lowest values for smooth concrete and mastic asphalt, especially when a thin slurry layer was present. Gate analysis mainly differentiated the flooring types by longer strides and better tracking on surfaces with higher friction and or abrasion. Step asymmetry was lower on floors with higher SRT values. However, with this study design, we were not able to analyze the long-term effects of flooring type on cow gait, because the cows had only a short daily contact with the test floors. None of the floors, except for the

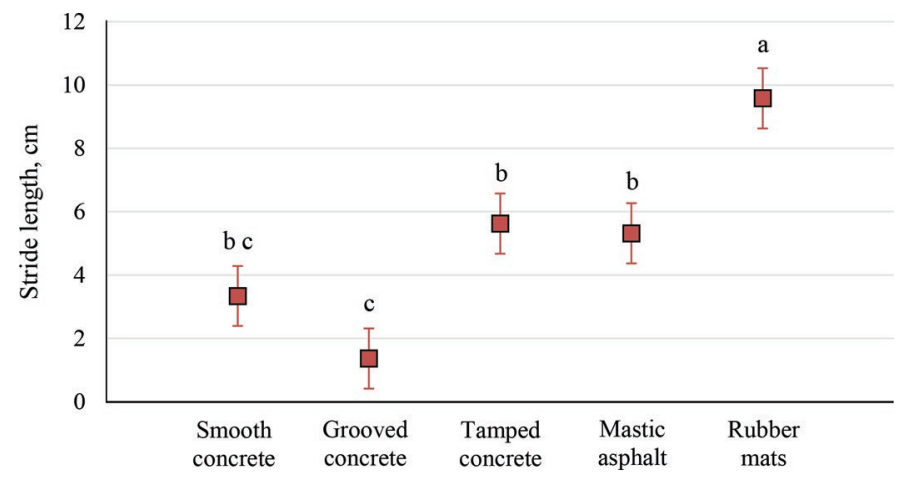

Figure 2. Stride length $(\mathrm{cm})$ on 5 different floors, presented as the difference from the baseline concrete slatted floor (LSM \pm SEM). Different letters $(\mathrm{a}-\mathrm{c})$ indicate values that differed significantly $(P<$ 0.05). Color version available online. 


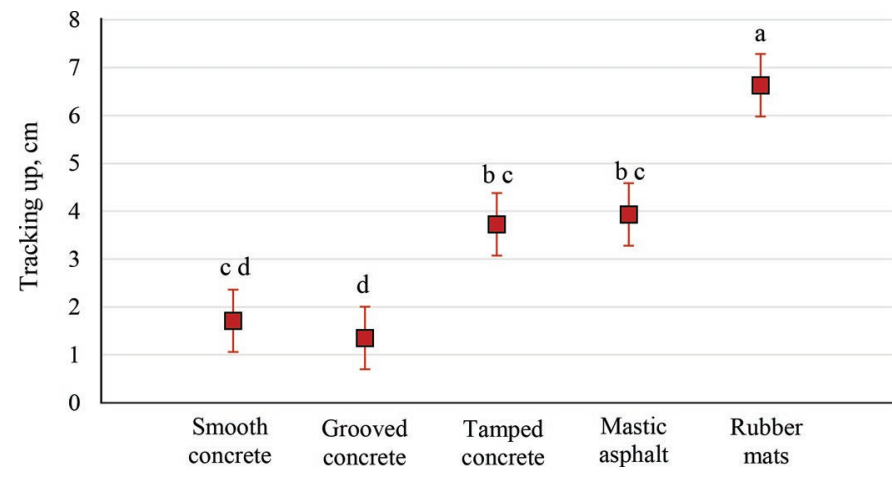

Figure 3. Tracking up $(\mathrm{cm})$ of cows on 5 different floors, presented as the difference from the baseline concrete slatted floor (LSM \pm SEM). Different letters (a-d) indicate values that differed significantly $(P<0.05)$. Color version available online.

concrete slats (baseline), was exposed to long previous usage and significant wear, which would also have influenced physical characteristics and results.

\section{Effects of Surface Microstructure}

The microstructure of the floor surface determines friction to a certain extent. A higher coefficient of friction for a floor surface is usually associated with longer strides and a more secure gait (Phillips and Morris, 2001; Rushen and de Passille, 2006; Haufe et al., 2009). Our results also revealed a significant positive correlation between higher coefficient of friction values, longer strides, and better tracking. The coefficients of friction for the concrete floors corresponded well with values obtained in other studies, even though measuring techniques differed. Furthermore, the DCOF was lower than the SCOF for the hard materials, in accordance with the theory (Chang et al., 2001). In most cases, this was also valid for rubber mats. However, as emphasized by Nilsson (1988), it is difficult to determine a SCOF on soft materials. Due to elastic deformation, only small

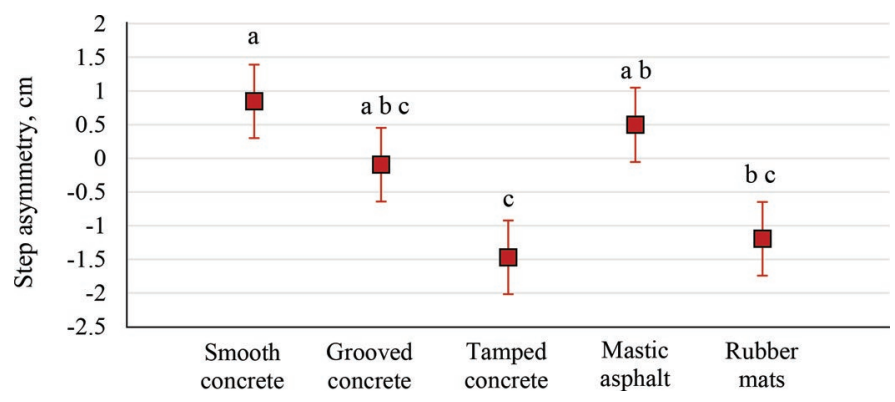

Figure 4. Step asymmetry $(\mathrm{cm})$ of cows on 5 different floors, presented as the difference from the baseline concrete slatted floor $(\mathrm{LSM} \pm \mathrm{SEM})$. Different letters $(\mathrm{a}-\mathrm{c})$ indicate values that differed significantly $(P<0.05)$. Color version available online.

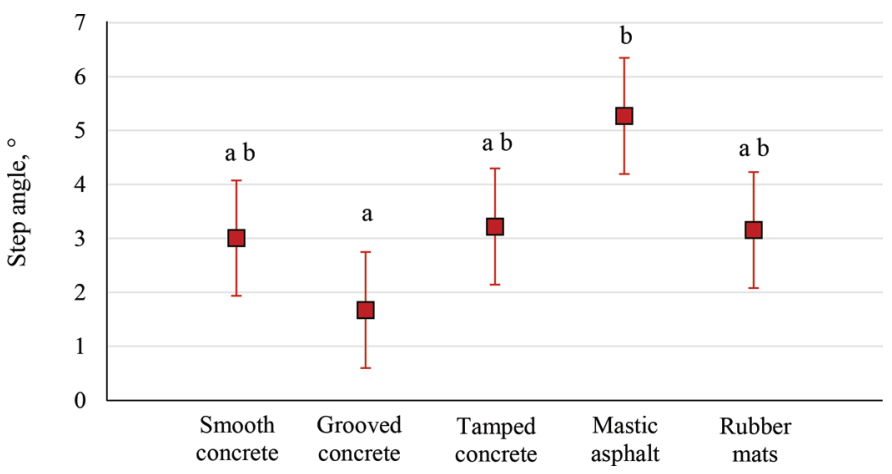

Figure 5. Step angle $\left(^{\circ}\right)$ of cows on 5 different floors, presented as the difference from the baseline concrete slatted floor (LSM \pm SEM). Different letters $(\mathrm{a}, \mathrm{b})$ indicate values that differed significantly $(P<$ $0.05)$. Color version available online.

differences between SCOF and DCOF were observed for soft flooring.

The better traction on tamped concrete we observed in the gait analysis was not correlated with the results of the friction tests, especially when a thin layer of slurry was present. Instead, on the hard floors, the abrasiveness was more strongly correlated with better gait. Abrasiveness (i.e., floor surface roughness) is often associated with greater slip resistance (Phillips and Morris, 2001). The roughness is especially important for better traction when a floor is soiled, because on such surfaces the hysteresis component and wear have a major effect on friction (Mckee and Dumelow, 1995). However, the effect of hysteresis was probably not adequately assessed in our drag test using a polymer artificial claw, because the elastomer of the friction tester was slightly harder than that of a claw horn (Borderas et al., 2004). However, in our trials, cows could distinguish between tamped concrete and other concrete floors and responded with longer strides and

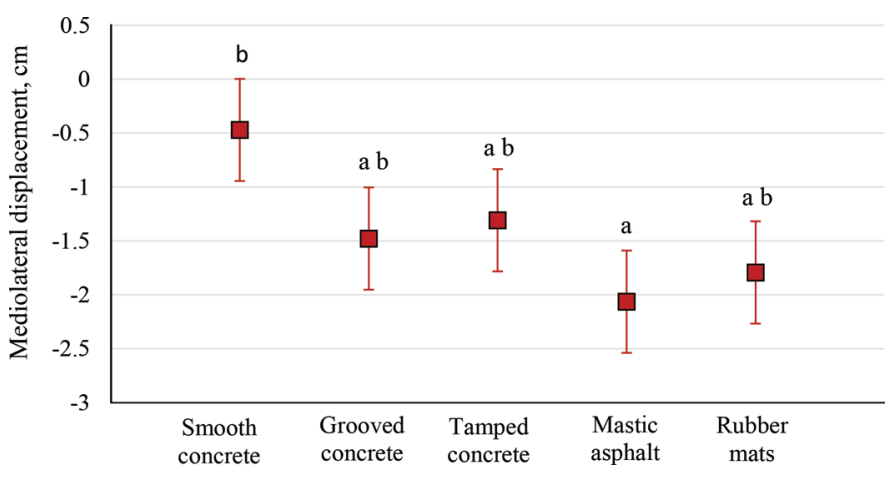

Figure 6. Mediolateral displacement of cow rear feet $(\mathrm{cm})$ on 5 different floors, presented as the difference from the baseline concrete slatted floor $(\mathrm{LSM} \pm \mathrm{SEM})$. Different letters $(\mathrm{a}, \mathrm{b})$ indicate values that differed significantly $(P<0.05)$. Color version available online. 
Table 3. Partial correlation coefficients (based on analysis of multiple regression) for relationships between physical characteristics ${ }^{1}$ under clean (dry) and soiled (slurry) conditions, and gait characteristics at an individual (within-cow) level

\begin{tabular}{|c|c|c|c|c|c|c|c|}
\hline Item & \multicolumn{2}{|c|}{ Dry } & \multicolumn{2}{|c|}{ Slurry } & $\begin{array}{c}\text { Dry } \\
\text { SRTv }\end{array}$ & $\begin{array}{l}\text { Slurry } \\
\text { SRTv }\end{array}$ & $\begin{array}{c}\text { Abrasion } \\
\text { dry }^{2}\end{array}$ \\
\hline Stride length & $0.54^{*}$ & $0.48^{*}$ & $0.48^{*}$ & $0.46^{*}$ & $0.39 *$ & $0.35 *$ & $0.28^{*}$ \\
\hline Step angle & 0.15 & 0.10 & 0.09 & 0.10 & -0.11 & -0.10 & $0.26^{*}$ \\
\hline Tracking & $0.49^{*}$ & $0.44^{*}$ & $0.44^{*}$ & $0.43^{*}$ & $0.42^{*}$ & $0.41^{*}$ & $0.24^{*}$ \\
\hline Step asymmetry & $-0.17^{*}$ & -0.12 & -0.13 & -0.12 & $-0.26^{*}$ & $-0.33^{*}$ & -0.06 \\
\hline
\end{tabular}

${ }^{1} \mathrm{SCOF}=$ static coefficient of friction, DCOF $=$ dynamic coefficient of friction, SRT $=$ skid-resistance test value measured on 6 different floors (smooth, grooved, and tamped concrete; mastic asphalt; rubber mats; and concrete slats).

${ }^{2}$ Excluding values obtained on rubber mats.

$* P<0.05$.

improved tracking, to the same extent that they did on mastic asphalt.

Mastic asphalt has more persistent friction characteristics and provides better traction than concrete (Haufe et al., 2009). At the same time, asphalt flooring with high abrasiveness can cause excessive wear, resulting in changes in claw conformation (Telezhenko et al., 2009) and in the biomechanical characteristics of the claw (Telezhenko et al., 2008). The asphalt flooring used in the present study had the highest abrasion, with rather high friction values, although the skid resistance was relatively low. Roughness is not always associated with higher SRT values (Franck et al., 2007), but the abrasiveness of the flooring had an effect on gait characteristics associated with the base of support, such as step angle and mediolateral displacement. Increased base of support indicates compensation for deficiencies in balance. However, both step angle and mediolateral displacement suggested a smaller base of support on asphalt, and step angle also had a significant relationship with abrasion value. Decreasing angle and increasing mediolateral displacement, as on smooth hard floors, keeps the center of mass over the base of support to prevent slipping (Grönqvist et al., 2001).

\section{Effect of Surface Macrostructure (Grooves and Patterns)}

The gait analysis revealed that cows walked with more confidence (longer strides) on tamped flooring than on grooved flooring. This was in agreement with Albutt et al. (1990), who showed that tamped concrete was more slip resistant than grooved. However, in the present study it was impossible to distinguish the effect of different type of grooves, because their effect was confounded by the roughness (microstructure) of the surfaces because of different concrete surface finishing. We used the same concrete floor surface for smooth and grooved concrete, but the process of tamping created a rougher surface (Albutt et al., 1990; Dumelow and Sharples, 1993). Cutting grooves is still the most commonly used method to improve traction on older concrete floors in walking areas for cattle, but very few studies have described the effect of grooved concrete in improving slip resistance (Dumelow, 1993).

Cows walked with longer strides on surfaces with higher friction or abrasion, but their step asymmetry, characterizing in-between limb coordination (Telezhenko, 2009), was greater on mastic asphalt and smooth concrete, the 2 hard surfaces without grooves or patterns. According to Mckee and Dumelow (1995), very rough floors and floors with draining grooves have an advantage over smooth surfaces when slurry is present, because of greater hysteresis on the rough surfaces. Although mastic asphalt provided the highest abrasion values, due to its fine finishing it was not rough enough to provide sufficient asperities into the claws when the floor was soiled. Both asphalt and smooth concrete were also discriminated by relatively low SRT values in the presence of slurry. Step asymmetry also had a negative correlation with SRT values, suggesting that better skid resistance resulted in less asymmetrical steps. It is possible that SRT values better reflect the slipperiness of the floor at the first claw-floor contact of a walking cow, due to higher contact velocity of the SRT. Gronqvist et al. (1999) reported that SRT had a mean sliding velocity of $2.8 \mathrm{~m} / \mathrm{s}$, much higher than the speed used in our friction coefficient tests $(0.02 \mathrm{~m} / \mathrm{s})$.

\section{Effect of Softness}

Several studies have shown a positive effect on cow locomotion from equipping concrete floors with rubber mats (Telezhenko and Bergsten, 2005; Flower et al., 2007). A study by van der Tol et al. (2005) showed that a cow requires a very high coefficient of friction during 
sudden movements such as turning to walk safely and avoid slipping. However, providing extremely high floor friction under animal housing conditions with the constant presence of slurry would also increase the risk of extreme claw wear and claw capsule damage (van Amstel et al., 2004). Another option for providing better traction is to allow the claw to sink into a soft surface (Nilsson, 1988). Among almost all flooring comparisons in the present study, rubber mats provided significantly better gait, especially in terms of longer stride, which is associated with better slip resistance (Telezhenko and Bergsten, 2005).

Several studies have shown higher activity and estrus behavior and general comfort on rubber surfaces compared with conventional concrete floors (Rushen and de Passille, 2006; Platz et al., 2008; Haufe et al., 2009). Unfortunately, however, it is often difficult to compare results, because rubber mats examined in different studies may differ in their degree of softness and quality. The rubber mats used in this study were of a type designed for lying surfaces rather than for walking areas. In a previous study, we found that $30 \mathrm{~mm}$ (including studs) mats, identical to those used in present study, showed a tendency to be preferred by cows to regular rubber mats in walking areas (Telezhenko et al., 2007). As well, the risk of slipping is reduced when walking on a surface with better compressibility (Telezhenko and Bergsten, 2005; Rushen and de Passille, 2006; Flower et al., 2007; Platz et al., 2008). The normal force used in drag tests in the present study to calculate coefficients of friction corresponded to the moment when the maximum horizontal force was applied by a cow walking in a straight line (van der Tol et al., 2005). However, the vertical loading during the drag test, and therefore deformation of the rubber surface, was much larger than the moment of movement when the maximum coefficient of friction was required and most slipping occurred (van der Tol et al., 2005). To better assess the dynamics of floor deformation providing grip to reduce the slip risk on soft floors, several tests with different loadings need to be performed in future studies.

\section{CONCLUSIONS}

Different solutions to secure safe walking in dairy cow housing showed varying performance. Increasing friction on the floors generally improved cow gait. However, a low coefficient of friction did not always coincide with inferior traction. Floor abrasiveness characterizes the roughness of the surface and may provide a more valid estimation of traction on hard floors than coefficient of friction. The presence of grooves improved skid resistance and between-leg coordination, but the skid resistance of solid floorings without patterns was compromised, especially when slurry was present. Providing a resilient surface, where the claws could sink deep enough, seemed to have the best effect on gait.

\section{ACKNOWLEDGMENTS}

This work was carried out as part of the "LAMECOW" project funded through the EC Framework V program (2002-2005) and by the Swedish Farmers' Foundation for Agricultural Research. Their support is greatly appreciated.

\section{REFERENCES}

Albutt, R. W., J. Dumelow, J. P. Cermak, and J. E. Owen. 1990. Slipresistance of solid concrete floors in cattle buildings. J. Agric. Eng. Res. 45:137-147.

ASTM International. 1993. Standard test method for measuring surface frictional properties using the British pendulum tester. ASTM E303-93. ASTM, West Conshohocken, PA.

Bergsten, C., E. Telezhenko, and M. Ventorp. 2015. Influence of soft or hard floors before and after first calving on dairy heifer locomotion, claw and leg health. Animals (Basel) 5:662-686.

Bland, J. M., and D. G. Altman. 1995. Comparing methods of measurement: Why plotting difference against standard method is misleading. Lancet 346:1085-1087.

Borderas, T. F., B. Pawluczuk, A. M. de Passille, and J. Rushen. 2004. Claw hardness of dairy cows: Relationship to water content and claw lesions. J. Dairy Sci. 87:2085-2093.

Chang, W. R., R. Gronqvist, S. Leclercq, R. J. Brungraber, U. Mattke, L. Strandberg, S. C. Thorpe, R. Myung, L. Makkonen, and T. K. Courtney. 2001. The role of friction in the measurement of slipperiness, Part 2: Survey of friction measurement devices. Ergonomics 44:1233-1261.

De Belie, N., J. J. Lenehan, C. R. Braam, B. Svennerstedt, M. Richardson, and B. Sonck. 2000. Durability of building materials and components in the agricultural environment, part III: Concrete structures. J. Agric. Eng. Res. 76:3-16.

Dumelow, J. 1993. Simulating the cattle foot floor interaction to develop improved skid resistant floors. Livest. Environ. 93:173-180.

Dumelow, J., and T. Sharples. 1993. Design loads for slatted floors in cattle buildings. J. Agric. Eng. Res. 55:171-175.

Flower, F. C., A. M. de Passille, D. M. Weary, D. J. Sanderson, and J. Rushen. 2007. Softer, higher-friction flooring improves gait of cows with and without sole ulcers. J. Dairy Sci. 90:1235-1242.

Flower, F. C., D. J. Sanderson, and D. M. Weary. 2006. Effects of milking on dairy cow gait. J. Dairy Sci. 89:2084-2089.

Franck, A., G. Opsomer, A. de Kruif, and N. De Belie. 2007. Frictional interactions between bovine claw and concrete floor. Biosyst. Eng. 96:565-580.

Grönqvist, R., W. R. Chang, T. K. Courtney, T. B. Leamon, M. S Redfern, and L. Strandberg. 2001. Measurement of slipperiness: Fundamental concepts and definitions. Ergonomics 44:1102-1117.

Gronqvist, R., M. Hirvonen, and A. Tohv. 1999. Evaluation of three portable floor slipperiness testers. Int. J. Ind. Ergon. 25:85-95.

Haufe, H. C., L. Gygax, B. Steiner, K. Friedli, M. Stauffacher, and B. Wechsler. 2009. Influence of floor type in the walking area of cubicle housing systems on the behaviour of dairy cows. Appl. Anim. Behav. Sci. 116:21-27.

Jönsson, B. 1998. Golv i häststallar-Utformning av stallgångsytor [Floor in horse stables - The design of aisle surfaces] Department of Agricultural Engineering, Uppsala University, Uppsala, Sweden. [In Swedish with an English summary]

Mckee, C. I., and J. Dumelow. 1995. A review of the factors involved in developing effective non-slip floors for pigs. J. Agric. Eng. Res. 60:35-42. 
Nilsson, C. 1988. Floors in animal houses. PhD Thesis. Swedish Univ. of Agric., Lund, Sweden.

Nilsson, C., and R. Jönsson. 1998. Floors in horse stables - The design of aisle surfaces. Page 7 in Proc. EurAgEng Conf., Oslo, Norway. EurAgEng, Cranfield, United Kingdom.

Palmer, M. A., G. Olmos, L. A. Boyle, and J. F. Mee. 2012. A comparison of the estrous behavior of Holstein-Friesian cows when cubicle-housed and at pasture. Theriogenology 77:382-388.

Phillips, C. J., and I. D. Morris. 2001. The locomotion of dairy cows on floor surfaces with different frictional properties. J. Dairy Sci. 84:623-628.

Platz, S., F. Ahrens, J. Bendel, H. H. Meyer, and M. H. Erhard. 2008 What happens with cow behavior when replacing concrete slatted floor by rubber coating: A case study. J. Dairy Sci. 91:999-1004.

Rushen, J., and A. M. de Passille. 2006. Effects of roughness and compressibility of flooring on cow locomotion. J. Dairy Sci. 89:29652972.

Rushen, J., and A. M. de Passille. 2009. Flooring options to minimize lameness and optimize welfare. WCDS Adv. Dairy Technol. 21:293-301.

Sprecher, D. J., D. E. Hostetler, and J. B. Kaneene. 1997. A lameness scoring system that uses posture and gait to predict dairy cattle reproductive performance. Theriogenology 47:1179-1187.

Telezhenko, E. 2009. Measurement of spatial gait parameters from footprints of dairy cows. Animal 3:1746-1753.
Telezhenko, E., and C. Bergsten. 2005. Influence of floor type of the locomotion of dairy cows. Appl. Anim. Behav. Sci. 93:183-197.

Telezhenko, E., C. Bergsten, M. Magnusson, and C. Nilsson. 2009. Effect of different flooring systems on claw conformation of dairy cows. J. Dairy Sci. 92:2625-2633.

Telezhenko, E., C. Bergsten, M. Magnusson, M. Ventorp, and C. Nilsson. 2008. Effect of different flooring systems on weight and pressure distribution on claws of dairy cows. J. Dairy Sci. 91:18741884.

Telezhenko, E., L. Lidfors, and C. Bergsten. 2007. Dairy cow preferences for soft or hard flooring when standing or walking. J. Dairy Sci. 90:3716-3724.

van Amstel, S. R., J. K. Shearer, and F. L. Palin. 2004. Moisture content, thickness, and lesions of sole horn associated with thin soles in dairy cattle. J. Dairy Sci. 87:757-763.

Van Breukelen, G. J. 2006. ANCOVA versus change from baseline had more power in randomized studies and more bias in nonrandomized studies. J. Clin. Epidemiol. 59:920-925.

van der Tol, P. P., J. H. Metz, E. N. Noordhuizen-Stassen, W. Back, C. R. Braam, and W. A. Weijs. 2005. Frictional forces required for unrestrained locomotion in dairy cattle. J. Dairy Sci. 88:615-624.

Vokey, F. J., C. L. Guard, H. N. Erb, and D. M. Galton. 2001. Effects of alley and stall surfaces on indices of claw and leg health in dairy cattle housed in a free-stall barn. J. Dairy Sci. 84:2686-2699. 